\title{
The effect of childhood education on old age cognitive abilities: evidence from a Regression Discontinuity design*
}

\author{
Fabrizio Mazzonna \\ Tor Vergata University
}

\author{
James Banks \\ University of Manchester and IFS
}

Draft version

October 22, 2010

\begin{abstract}
We exploit the change to the minimum school-leaving age in the United Kingdom from 14 to 15 using a regression discontinuity design to evaluate the causal effect of one more year of education on cognitive abilities at older ages. We find a large and significant effect of this reform on memory and executive functioning measured using simple cognitive tests from the English Longitudinal Survey on Ageing (ELSA). This result is particularly remarkable since the 1947 reform had a powerful and immediate effect on about half the population of 14 -year-olds. We investigate and discuss the potential channels by which this reform may have had its effects, as well as carrying out a full set of sensitivity analyses and robustness checks.
\end{abstract}

Keywords: Cognitive abilities; education; aging; regression discontinuity design; ELSA.

JEL codes: C14, I28, J14, J24.

\footnotetext{
${ }^{*}$ Acknowledgements: We are grateful to Janet Currie and Franco Peracchi for comments on early drafts of this work. We are also grateful to the audience of the 2010 RAND Workshop on Comparative International Research Based on HRS, ELSA and SHARE. Banks is grateful to the Economic and Social Research Council and the US National Institute on Ageing for funding his research on this project. Data from the English Longitudinal Study of Ageing were supplied by the ESRC Data Archive. ELSA was developed by researchers based at University College London, the Institute for Fiscal Studies and the National Centre for Social Research, with funding provided by the US National Institute on Ageing and a consortium of UK government departments coordinated by the Office for National Statistics. Responsibility for interpretation of the data, as well as for any errors, is the authors' alone.
} 


\section{Introduction}

The association between schooling and many positive economic, social and health outcomes is well documented. Although this association needs to be interpreted with caution because of the indirect effect of unobserved factors or of reverse causality, the economic literature has recently been able to identify a causal effect of education on many of these outcomes, often through the use of an estimation strategy based on exploiting "exogenous variations" in schooling. One leading example is that of changes to compulsory schooling laws. These laws are ideal instruments not only because they allow the evaluation of the exogenous effect of one more year of education, but also because they allow the evaluation of the efficacy of such a policy change. Several papers have consistently estimated gains to adult outcomes from compulsory schooling in terms of earnings (Angrist and Krueger, 1991; Acemoglu and Angrist, 2001; Oreopoulos, 2006), crime (Lochner and Moretti, 2004) and health (Lleras-Muney, 2005). From a policy point of view, these outcomes are also motivations behind compulsory schooling laws.

However, not all of the potential benefits from such policies have been explored. In particular, the effect of schooling on old age cognitive abilities is missing, though this effect should be of an increasing interest in a aging society. Cognitive abilities, in fact, are fundamental for decision making and then a crucial element for the appropriate formulation of consumption and saving plans (Banks et al., 2007). Such individual or household decision-making skills are arguably becoming more important for older individuals with the increasing importance of individual provision, and the declining importance of state provision, in social security and healthcare systems around the world. More generally, cognitive abilities may be regarded as one aspect of human capital, along with education, health, and non-cognitive abilities.

For this reason, in this paper we analyze the effect of the 1947 British compulsory school reform which increased the minimum school leaving age from 14 to 15 years old, presenting new evidence of the causal relationship between early life education and late life cognitive skills. We use this law change for two main reasons. First, it was targeted at the least educated groups and specifically aimed at affecting subsequent physical and mental trajectories as clear from the government's motivations reported by Oreopoulos (2006): “. . improve the future efficiency of the labor force, increase physical and mental adaptability, and prevent the mental and physical cramping caused 
by exposing children to monotonous occupations at an especially impressionable age. ". Second, as stressed by Oreopolous (2006) the 1947 British school law affected a very large proportion of the 14 years old population - decreasing by around 50 percentage points in one year the proportion of people who left full-time education before age 15. We exploit this dramatic change in education attainment using a fuzzy regression discontinuity (FRD) design to evaluate the causal effect of the additional year of schooling induced by the reform on old age cognitive ability. Although it is not a "sharp" design, because the increase in educational attainment did not affect the entire population involved by the reform, the large proportion affected is especially important in comparison to similar US compulsory school changes that affected only about $5 \%$ of the relevant cohorts (Lleras-Muney, 2005). This difference is particularly important if the effect of interest is not homogeneous across the population since our estimation strategy allows us to recover only local effects (LATE) instead of averages across the population (ATE) (see Imbens and Angrist, 1994). As a consequence, a local parameter based on such a large proportion of the population should be more relevant then one based on a very small subgroup as in the US case.

We find that the UK compulsory school law change of 1947 had a quite large impact, around half of standard deviation, on memory and executive functioning at older ages measured using some cognitive tests from English Longitudinal Survey on Aging (ELSA). Given this perhaps surprising finding, we engage in a full battery of sensitivity and robustness tests. In order to test for confounding factors we look for potential effects of the reform on other variables - in our case fathers occupation and childhood health at age 10 - that might be thought to be predetermined and operating independently of the reform. In addition we look for discontinuities at dates-of-birth other than the cut-off around which the reform was defined, consider a broad range of linear and polynomial trend controls, and consider subsamples defined by different sized windows on either side of the reform and by the exclusion of those with high education levels. None of these tests provide any basis on which to doubt the empirical findings.

In our analysis we try to rule out some possible explanation for these results. In particular, we analyze the possible channels through which education would have affected old age cognitive abilities. The income channel is the more reasonable due to the estimated large impact of the 1947

\footnotetext{
${ }^{1}$ This quote also makes it clear that, as well as providing one year of extra schooling this reform will have typically led to a one-year increase of age of entry into the labour force which may be considered beneficial if paid work at young ages is thought to be harmful. Obviously our analysis will not be able to distinguish between which of these two changes led to any identified effects on outcomes, although we do return to this issue briefly in our discussion.
} 
reform on earnings (Oreopoulos 2006). We found some positive effects of the reform on males' social and cultural participation and engagement. We exclude, instead, the health channel. In addition to poor evidence found for the effect of the reform on many health outcomes in other analyses (Clark et al., 2008; Jürges at al, 2009), we do not find significant effect of the reform on late-life subjective wellbeing and quality of life using a measure (CASP 19) that is known to be highly correlated with many health outcomes (Wiggins et al., 2008).

The remainder of this paper is organized as follows. Section 1.1 presents a brief literature review on the relationship between schooling and cognitive abilities. Section 1.2 discusses the main features of the 1947 UK school reform and Section 2 describes the data used for our analysis. Section 3 describes the empirical strategy adopted in this paper and main identification issues and Section 4 presents our results. Finally, Section 5 offers some conclusions and a discussion about the results we find in this paper.

\subsection{Education and cognitive abilities}

The relationship between schooling and cognitive abilities is one of the more studied issue in both psychology and economics. The controversial book "The Bell Curve" by Murray and Herrnestein (1994) claims that education does not affect cognitive skills. According their view, intelligence, measured by IQ is fixed at a relatively early age (around age eight). This implies that intelligence is mainly responsible for students staying in school and for people economic and social achievements. Different evidence comes from Ceci and Williams (1997) that report some evidence of a bidirectional relationship between schooling and intelligence which affects variations in economic outcomes.

In the labor economics literature a large debate concerns whether schooling plays a role mainly as a market signal of innate ability or as way to improve on skills. For this reason, many efforts have been concentrated on assessing the economic return to education controlling for endogeneity due to unobserved ability (Ashenfelter and Rouse 1999; Card 2001; Oreopoulos 2006). This literature clearly identifies a causal effect of education on earnings but even this could not be considered an evidence of an effect of schooling on cognitive skills since such an effect would be predicted by a signaling model (Spence 1973) in which schooling emerges as a signal that an agent sends about her ability level to the employer. In that case, schooling may allow individuals to obtain those formal qualifications required to apply for higher earnings job.

Cunha and Heckman $(2007,2008)$ build an analysis that draws a distinction between innate 
ability and acquired skills. "Abilities are created, not solely inherited, as interaction between genes and environment" to produce cognitive and non cognitive skills that have both a genetic and an acquired character. They show evidence of critical and sensitive periods in skill formation and dynamic complementarity in investments. The main consequence of their findings is the importance of early life intervention in particular for the subsequent evolution of cognitive abilities. They show that returns to late childhood investment for young adolescents from disadvantaged backgrounds are very low compared with the returns to early investment. Not less important is the role of non cognitive abilities that are responsible for performance in many economic, health and social achievements. Recently, Heckman et al. (2010) show that the Perry Preschool Program, which enhanced the subsequent economic and social performance of participants, did not boost participant adult IQ but only their non-cognitive abilities.

Even less clear is the relationship between schooling and old age cognitive abilities, which is the main target of our work. Many empirical studies (Le Carret 2003, Mazzonna and Peracchi 2009) underline the positive association between education and old age cognitive abilities, but only Glymour et al. (2006) find evidence of a causal relationship between education and memory. Exploring the geographical variation in compulsory school reform across US they found a positive effect of one more year of education on memory test scores using HRS data. However, estimated effects are based on an instrument (the compulsory school reforms in US) that only affects a very low proportion of the population (see next section for more detail). Not less problematic is the use of a separate-sample instrumental variable (SSIV) estimator, in which the first step is estimated using the 1980 US census $5 \%$ sample.

More generally, it is not clear the mechanism through which education might affect old age cognitive abilities. Mazzonna and Peracchi (2009) apply the Grossman model of health capital to cognitive outcomes in order to generate empirical predictions about the evolution of cognitive abilities at older ages. In that framework there are multiple channels that can be identified: productive efficiency; employment, type of occupation and earnings; preferences towards social and cultural stimulating activities. The direct effect of the reform in this case would be through productive efficiency, which means that more schooling allows individuals to obtain better health from a given amounts of inputs. However, this concept does not seem so clear when the application is to cognitive outcomes rather then health.

The occupation channel is perhaps more interesting. In a signaling model, schooling through 
formal qualification could allow individual to apply for higher earning jobs and such jobs could positively affect cognitive abilities particularly at older ages if they are more cognitively demanding. However, the changing nature of education signals over time when cohorts are affected by reform would need to be borne in mind in making any more formal statements along these lines. And, as we explain in the next section, the 1947 UK reform does not imply any formal qualification for the affected students so signals may not be particularly strong. On the other hand Oreopoulos (2006), exploiting the same reform, found a significant and large effect (around 15\%) of the additional year of schooling on earnings. To the extent that these greater earnings are associated with either higher rates of employment, or more cognitively demanding jobs amongst those employed, then these two factors may protect against cognitive decline at older ages (Mazzonna and Peracchi, 2009; Willis and Rohwedder 2010).

A similar set of considerations apply to the third channel, i.e. social and cultural participation. The positive effect of such type of activities has been extensively described by Hertzog et al. (2008) in a comprehensive review of cognitive-enrichment effects at old ages. The general idea being that education could affect the parameters of the utility function thus increasing the utility derived from more cognitive demanding activities and consumption (e.g. reading newspapers, using the internet or engagement in social and cultural organizations, club or societies).

The last channel we consider is health. If the reform improved health trajectories of the affected population this may also have an effect on cognitive abilities at older ages. However, using many waves of Health Survey of England (HSE) Jürges et al., (2009) and Clark et al., (2008) do not find any significant effects of the same 1947 reform on many health outcomes (mortality, blood pressure, self-assessed health and some biomarkers). Given this lack of evidence on physical health we explore a more global measure of subjective wellbeing and quality of life, the so-called CASP19 index which captures Contol, Self-Realisation, Autonomy and Pleasure (see Appendix A). This measure is particularly important in an aging society where living longer is no more enough, and quality of life during the old age it is recognized to be equally important (Hyde et al. 2003).

\subsection{UK school leaving age reform}

Legislation from UK's 1944 Education Act raised the minimum school-leaving age in England, Scotland and Wales on 1st April 1947 from 14 to 15 years old. This law and its implementation was largely discussed in many works which use the same exogenous variation in compulsory schooling 
as instrument for identification of the effect of education on income and health (Oreopolous, 2006 and 2007; Jürges et al., 2009; Clark et al., 2008). For this reason we only briefly discuss the main points of this reform.

Basically, the reform implies that, whilst children born before 1st April 1933 could leave school when they turned 14, those born after that date could not leave until they turned 15. As stressed by Oreopoulos (2006), this law change affects a large proportion of the population. Figure 1 shows the fraction of males and females that left full time education by the age of 14. Using ELSA data, the figure displays averages at quarter of birth level with the vertical black line that marks the exact cutoff point at 1st of April 1333. It is evident that before of the reform implementation about $60 \%$ of the population left the school at age of 14 , while after its implementation this proportion dramatically decrease below $10 \%$.

This "success" was made possible through a "national operation that expanded the supply of teachers, buildings and furniture (Oreopoulos 2006). This proportion is particularly important if compared with similar US compulsory school changes used in the literature (Lleras Muney, 2005; Glymour 2006) that affected only $5-10 \%$ of the relevant cohorts.

Age at school entry, instead, remains unchanged: students must have started school by the term in which they turns the age of 5 . Actually, a similar rule applies also for age at school exit: students could leave the school only at end of the term in which they turn the minimum school leaving age (14 before the reform, 15 after).

Its important to underline that this increase in compulsory schooling did not lead to identifiable formal qualifications for the cohort involved. At that time, students could obtain a formal high school degree not before the age of 17 . As a consequence, students involved by the increasing in compulsory schooling had to stay at least two more years at school in order to obtain a formal qualification.

A last important remark relates to the timing of the reform, in the context of the main identifying assumption that allow us to identify the causal effect of education on cognitive abilities (see for more details section 3.2), namely the absence of other unobserved changes at the time of the reform (or more precisely, to the cohorts treated by the reform at any point in their lifetimes) that might also have affected cognitive abilities. Some important events happened during that period that involve the cohorts of interest. They were born a few years after the Great Depression, and affected by rationing and bombing during WWII, but without being involved in fighting. However, exposure 
to these circumstances was very similar for cohorts born on either side of the 1 April 1933 cutoff (Clark and Royer, 2008) and we will be including flexible trend variables throughout our analysis to control for gradual changes across date of birth cohorts. Moreover, as in Jürges et al. (2009), we condition our estimates on adult height to control for both economic and disease environment in childhood (Case and Paxson 2009). Finally, we take care to to ground our estimation strategy on a narrow interval around the reform as not to potentially confound the effect of the reform with that of other unobservables.

\section{Data and summary statistics}

\subsection{Data}

Our data come from the first 3 waves $(2002,2004,2006)$ of the English Longitudinal Study of Ageing (ELSA) a multidisciplinary survey of health, economic position and quality of life as people age. Its target population consists of people aged 50+ living in private households in England at baseline, plus their co-resident partners. The survey sample was drawn from respondents to the Health Survey for England (HSE). Around 12,000 respondents were recruited from three separate years $(1998,1999,2001)$ of HSE.

The topic areas covered in the main questionnaire include: individual and household characteristics; physical, cognitive, mental and psychological health; social participation and social support; housing, work, pensions, income and assets; and expectations for the future. All data are collected by face-to-face, computer-aided personal interviews (CAPI), supplemented by a self-completion paper-and-pencil questionnaire that is left behind at the interview and subsequently returned by respondents.

This last element is used to collect information on factors such as quality of life, psychosocial wellbeing, social participation, mobility, life satisfaction, perceived social position, social networks and social capital. Due to the survey design, not all individual respond to the self-completion questionnaire - in our sample we have a non response rate of around 15\%. From this questionnaire, we make use of a well recognize measure of quality of life, the so called CASP 19, and an index for social and cultural participation. CASP 19 is an acronym for Control, Autonomy, Self-Realization and Pleasure and it is a 19-item scale derived from questions about aspects of life that people in theirs 60s reported as important in qualitative studies. The index for social and cultural participation is 
based on a selection of 8 questions about social and cultural activities. We refer to Appendix A for more details on the construction of these two variables.

Our analysis uses various subsamples of the ELSA data according to the various specifications. Firstly, we define samples according to birth cohort. We consider different cohorts ranges, selecting from one year on either side of the cutoff date of 1st April 1933 (i.e. those born from 1 April 1932 to 31 March 1934) to 10 years on either side. The exact cohort range also depends on the estimation method in use (i.e. whether we use local linear regression or polynomial regression).

A second sample selection criteria is based on educational attainment. One feature of our data is that education is recorded as the age at which the individual completed full-time education, with the data being truncated from above and all values of 19 or higher being grouped together as a single categorical values for 19 or more. Since we are mainly interested in the lower educated groups who will have been the ones affected by the reform, we construct 3 different sample selections for analysis. The first is simply the whole sample, regardless of their age left education. A second subsample is limited just to those that left full time education before the age of 19 ( age left $<19$ ). In this case we exclude from the sample all individuals with at least some college attainment, but still include many respondents that would have left school after the age of 15 regardless of the reform (these are sometimes known as "always-takers"). The last and most restrictive subsample excludes all individuals who left full time education after the age of 15 ( age left $<16$ ). Since we can only estimate local average treatment effects and this sample should contain the biggest concentration of "compliers", i.e. those that increase their educational attainment by one year only as a consequence of the reform, this last group is the most important sample from the point of view of our estimation strategy.

The educational breakdown underlying these three subsamples is shown in Table 1 which shows the distribution of age left education in our sample for the cohorts born between 1930 and 1936, split by sex and whether the cohorts were born before or after the reforms cutoff date. It is clear that the big change in educational attainment following the reform is from 14 to 15 . This is particularly true for males, where the fractions leaving school at older ages in the 'after' cohorts are only increased very slightly. The distribution of educational outcomes across the reform dates for women is slightly different with the reduction in the proportion leaving at age 14 being accompanied by a large increase in the proportion leaving at age 15 but also a not insubstantial increase in the proportion of women leaving school between 16 and 18. We return to this fact later in our discussion. 


\subsection{Cognitive measures and descriptive statistics}

The ELSA cognitive function module contains measures of cognitive function based on simple tests of memory, word-finding ability, executive function, speed of processing and numerical ability. The memory assessment is subdivided into retrospective memory (recalling information that was learned previously) and prospective memory (remembering to carry out an intended action). The executive function tests refers to a number of cognitive control processes, which include attention, initiation, mental flexibility, organization, abstraction, planning and problem-solving. The test format adopted by ELSA is based on the Telephone Interview of Cognitive Status-Modified (TICSM) test which utilizes a format for the assessment of cognitive functions that can be administered in person or by telephone and is highly correlated with the Mini-Mental State Exam (MMSE) (Folstein et al. 1975), a screening tool frequently used by health-care providers to assess overall brain function.

The tests are comparable with similar tests implemented in the HRS and SHARE, and follow a protocol aimed at minimizing the potential influences of the interviewer and the interview process.

We exclude from our analysis the tests of orientation in time and prospective memory because they show very little variability across respondent. We exclude also the numeracy test because it was administered only in the first wave of the survey (as well as wave 4 although we are not using that data in our analysis). As a consequence, we evaluate the effect of the increase in compulsory school reform on two different cognitive domains: memory and executive functioning. The memory tests consist of verbal registration and recall of a list of 10 items. The respondent hears the list only once. The speed at which these words are displayed to the interviewer and then read out to the respondent is automatically controlled by the CAPI system. The test is carried out immediately after the encoding phase (immediate recall), and then again after the the other cognitive questions (delayed recall). ELSA uses the same word lists as the Health and Retirement Study in the US, which comprise four different versions so that different lists can be given to different members of the same household and to the same individual over time. Repeated exposure to the same tests, in fact, may induce learning effects which are likely to improve the cognitive scores of some respondents over time. From these two tests we calculate a Memory score as the sum of the number of target words recalled in the two recall phases (immediate and delayed). This score can, and does, range from 0 to 20. 
Executive functioning is assessed using two different tests, namely verbal fluency and letter cancellation. The verbal fluency test is a test of how quickly participants can think of words from a particular category, in this case by counting how many distinct elements from the animal kingdom (real or mythical, except repetitions or proper nouns) the respondent can name within one minute. This test requires self-initiated activity, organization and abstraction and set-shifting (Steel et al., 2004). Letter cancellation is a test of attention, visual search and mental speed. The participant is handed a clipboard to which is attached a page of random letters of the alphabet set out in rows and columns, and is asked to cross out as many target letters ( $\mathrm{P}$ and $\mathrm{W})$ as possible within one minute. The page comprises 26 rows and 30 columns, and there are 65 target letters in all. Respondents are asked to work across and down the page as though they were reading and to perform the task both as quickly and as accurately as possible. The total number of letters searched provides a measure of speed of processing, while the number of target letters ( $\mathrm{P}$ and $\mathrm{W})$ missed up by the respondent provides a measure of accuracy.

As in Steel et al. (2004), an executive function index has been derived from the verbal fluency and letter cancellation test together. Our index is constructed by summing the two standardized scores (constructed by subtracting off their mean and dividing for the standard deviation). We tried also other methods of aggregation that we do not report to conserve space. One nice feature of the scores obtained from both memory and executive function is the fact that they do not suffer from floor or ceiling effects, that usually characterize other measures of cognitive functioning like the MMSE (de Jager et al. 2003).

Table 2 shows means and standard deviations of our test scores by age of leaving full time education and sex, for people born five years before and after the cutoff date of 1st of April 1933 . The first set of rows reports these statistics for the full sample, while the second and the third sets report the same statistics conditional on leaving school before 19 and 16 years old, respectively.

Finally, Table 3 reports means comparison between treatment groups for our cognitive and noncognitive outcomes and other predetermined individual characteristics. We report these statistics for respondents born 5 years before and 5 years after the cutoff date. The first set of rows (age left $<19$ ) reports the means comparison for those that left full time education before the age of 19 , while the second set (age left $<16$ ) reports the same comparison for those that left before 16 . The predetermined characteristics are childhood health (self-assessed by the responded) and father's last

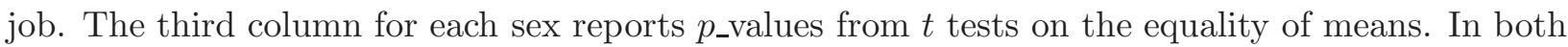


educational groups and for both sexes, this tests reject the null of equality of means (at the 1 percent level) for both our cognitive test scores. Similar results are apparent for social participation where, except for males in the lower educational subsample, we reject the null of equality of means at least at $5 \%$ level. The quality of life measure (CASP19), however, does not show significant differences between the two groups, except for females with educational attainment. Finally, the characteristics we consider to be predetermined seem to be balanced between the two groups. This is fundamental for our analysis, because a different result would have cast doubt about the unconfoundedness hypothesis, the main assumption of our estimation strategy, as discussed in section 3.2. However, this kind of comparison is purely descriptive because does not take account of cohort trends in such variables so we return to this test later when we estimate full models with control variables.

\subsection{Graphical analysis}

To examine the effect of law change on educational attainment we present a set of descriptive figures that shows the relationship between birth cohort and different educational outcomes. In each graph points represent means among people in each quarter of birth cell, with the sample covering the period 6 years before and after the the cutoff date of 1st of April 1933. Purely for descriptive purposes, the fitted lines is based on a local linear fit on 6 years before and after the reform. The vertical line denotes the cohort of birth cutoff for the law change (2nd quarter of 1933). As seen before, the discontinuity presented in Figures 1 on the fraction leaving full-time education by age 14 is evident for both males and females. Before the reform about $60 \%$ of the individuals left full time education by age 14. After the reform this fraction collapses to below $10 \%$.

At the same time, however, the reform generated a small positive spillover to higher level of education. As discussed earlier, the Figure 2 shows that the reform had a small effect on the female fraction leaving full-time education by age 16, but no effect on this fraction for males. On the contrary, the discontinuity is amplified if we consider only people that left full time education before the age of 16 as in figure 3 . The jump at the discontinuity point is almost sharp, from about $80 \%$ to $10 \%$. The effect of the reform on this subsample is particularly important because this subsample relates to the most affected people, i.e. those who, without the reform, would have been most likely to leave the school by age 14 .

The second set of descriptive figures show the discontinuity in the cognitive scores of interest. Figures 4 and 5 show the discontinuity in memory score conditional on leaving school before the 
age of 16 and in the full sample while Figure 6 and 7 show the same discontinuities for the executive function score. All figures show a very high variability in cognitive tests score averages.

This high variability may be the results of different factors. First, it may be due to a small number of observation per cell (an average of 36 observation for each month of birth). A second possible explanation may be the presence of cyclical component in quarter of birth, as suggested by Cunha and Heckman (2007). Third, as explained in Section 1.2, ages at school entry and exit vary according to a set of rules depending on of birth (Clark and Royal 2008). These rules generate a lot of variability in the total months spent at school within each cohort but do not affect the validity of our estimation strategy, because the rules themselves did not change with the compulsory school reform of 1947. Finally, we could have a selection effect due to differential mortality rates, particularly for the older cohort. This issue is discussed in more detail in Section 3.2, but it is clear that this selection effect will become less important as our estimation strategy focuses on tighter and tighter intervals around the discontinuity.

The descriptive analysis presented in figures 4 and 5 suggests that, even though less immediately evident, the discontinuity in memory, especially for males follows the same patterns that we have seen in the educational figures. As with education, the effect on memory for males is evident only conditional on leaving before the age of 16 , while there are some positive spillover also for females with higher educational attainment. This consistency between the discontinuity in education and cognitive abilities is important because a different evidence would have cast doubt on the unconfoundedness hypothesis. In the case of executive function, although the fitted lines in figures 6 and 7 predict discontinuities in this test very similar to those in memory, they are clearly less evident because of the high variability in quarter of birth averages. For this reason, in figures 8 and 9 we show the same discontinuities in executive function as in figure 6 and 7 , but reporting six month averages on a 16 years interval. Although the variability in executive function averages is still present, the discontinuity for males conditional on leaving before 16 is now more evident. Finally, it is important to remark that even using an higher order polynomial fitting or using a year-of-birth instead of quarter-of-birth level of aggregation does not change the message from the graphical evidence. In order to save space this analysis is not presented. Instead we move on to our full empirical models with a more complete set of control variables and specification tests. 


\section{Empirical strategy}

\subsection{Regression discontinuity design}

The nature of the reform clearly makes it a candidate for a Regression discontinuity (RD) design providing us the opportunity of estimating the effect of one more year of schooling on old age cognitive abilities under relative weak conditions that we discuss in the next section. The general idea in $\mathrm{RD}$ design is that the probability of receiving a treatment (an additional year of schooling) is a discontinuous function of a continuous treatment determining variable (day of birth). However, the treatment in our case does not change from 0 to 1 at the cutoff point (1st April 1933). Following Angrist and Imbens (1994), we have people that regardless of the reform decide to stay at school also over the minimum compulsory school leaving age ("alway-takers"). There are also few people that regardless of the reform leave the school before the minimum compulsory age ("never-takers"). In such case the Fuzzy regression discontinuity (FRD) design is appropriate because it allows for a smaller jump in the probability of assignment to treatment at the cutoff. In the case of a binary treatment FRD design may be seen as a Wald estimator (around the discontinuity $c$ ):

$$
\tau_{F R D}=\frac{\lim _{x \downarrow c} E(Y \mid X=x)-\lim _{x \uparrow c} E(Y \mid X=x)}{\lim _{x \downarrow c} E(W \mid X=x)-\lim _{x \uparrow c} E(W \mid X=x)} .
$$

where, in our case, $c$ is the cutoff point; $X$ is the date of birth; $W$ is the treatment (one more year of education). Specifically, we estimate the following two equations:

$$
\begin{gathered}
Y_{i c s}=\alpha_{0}+\alpha_{1} E_{c s}+f\left(R_{i c}\right)+X_{i c t}^{\prime} \alpha_{2}+u_{i c s} \\
E_{i c s}=\gamma_{0}+\gamma_{1} Z_{c s}+g\left(R_{i c}\right)+X_{i c t}^{\prime} \gamma_{2}+\nu_{i c s}
\end{gathered}
$$

where $Y_{i c s}$ and $E_{i c s}$ are the cognitive scores and the educational level of the individual $i$, of the cohort $c$, in the survey year $s ; Z$ is a dummy variable equal to 1 for individuals born after the cutoff point; the running variable $R$ is an individual birth cohort (measured in months) relative to the cutoff; the vector $X$ contains pre-determined characteristics such as survey year and adult height. The function $f($.$) and g($.$) capture the relationship between birth cohort and respectively$ cognitive outcome and educational attainment. Notice that substituting the treatment equation into the outcome equation yields the reduce form:

$$
Y_{i c s}=\beta_{0}+\beta_{1} Z_{c s}+h\left(R_{i c}\right)+X_{i c t}^{\prime} \beta_{2}+\epsilon_{i c s},
$$


where $\beta_{1}=\alpha_{1} * \gamma_{1}$. The parameter of interest is $\alpha_{1}$ and its estimation, is the ratio of the reduced form coefficient $\beta_{1} / \gamma_{1}$.

We estimate the parameter of interest $\alpha_{1}$ using two different methods as suggested by Lee and Lemiux (2009). The first is based on a local linear regression around the discontinuity choosing the optimal bandwidth in a cross-validation procedure that we report in Appendix C. The second method makes use of the full sample ${ }^{2}$ using a polynomial regression in which the equivalent of the bandwidth choice is the choice of the correct polynomial order (see appendix D). In both cases, we estimate the treatment effect using 2SLS which is numerically equivalent to computing the ratio in the estimated jump (at the cutoff point) in the outcome variable over the jump in the treatment variable, provided that the same bandwidth or the same polynomial order is used for both equations. This allow us to obtain directly the correct standard errors that are robust and clustered at individual level. Controlling for clustering is particularly important in this setting because we have two possible sources of serial correlation, within individual overtime and across individuals in the same month of birth ${ }^{3}$. The first best in this case would be clustering at the higher level of aggregation that corresponds to the month of birth level. However, the number of clusters would be too small to have the consistent variance matrix estimator, in particular when we focus our analysis on a very small bandwidth around the discontinuity. For this reason we control for the larger source of correlation that is across the same individual over time. Not less important, we fully interact the polynomial $f($.$) and g($.$) . Otherwise, we are imposing the restriction that the$ slope coefficients are the same on both sides of the discontinuity point.

\subsection{Identification issues}

The attractive feature of this estimation strategy is that provide estimates that are "as credible as those from randomized experiment" (Lee and Card, 2008) under relative weak assumptions. The key assumption is that the conditional expectation of the potential outcomes (age left full time education and cognitive scores) with respect to the treatment determining variable (birth cohort) are smooth (continuous) function at the threshold $(R=0)$. This allows us to attribute any discontinuity in the outcomes of interest at the threshold only to the effect of the reform. As with

\footnotetext{
${ }^{2}$ In reality, we restrict the sample to 10 years before and after the reform because we have few observations for cohorts before the 1923

${ }^{3}$ the discreetness of our treatment determining variable (month of birth) can introduce a common component of variance for all the observations at any given value of this variable (Lee and Card 2008).
} 
any identification assumption this is directly untestable but, as common in the literature (Lee and Lemieux, 2009), we can employ some indirect tests. We test whether there are discontinuities in predetermined characteristics for which we have data, but which are known not to have been affected by the treatment. We have already seen in Table 3 that means comparison in pre-determined characteristics like childhood health and father's last job do not reject the null hypothesis of equal means. We therefore tested the assumption of zero effects on these pre-determined characteristics using the same estimation strategy used for estimating the treatment effect on cognitive test scores. Also in that case, the results, reported in Appendix B, does not reject the null of zero effects.

Perhaps more importantly, since our population is made up of older individuals, the main concern about this assumption regards a possible selection effect due to mortality. This selection effect could have two different sources. The first is the differential in mortality rates between cohorts on the two sides of the discontinuity. In particular, older cohorts (i.e. on the left hand-side) could be more affected by mortality between the time of the reform and the time our outcome variables were observed (i.e. 2002-2006). However, focusing our estimation on a narrow interval around the discontinuity or conditioning for higher order polynomials of date of birth (when we increase the bandwidth) should allow us to control for the broad cohort pattern of differential mortality rates rather well, and discontinuities are unlikely to remain after these controls. Moreover, it is reasonable to assume that this selection mechanism is likely to affect mainly people with poor health and poor cognitive abilities (i.e. any selection would be a positive selection on survival). Since mortality is greater amongst the older cohorts on the left side of the discontinuity this implies that any estimated effect of education on cognitive abilities would, if anything, most likely be a downward biased estimate of the true effect.

The second concern about mortality is due to the possible existence of a causal effect of the reform itself (through education) on mortality. However, this second concern was ruled out by Clark and Royal (2008) who analyze the effect of the 1947 reform on mortality in detail. They find that, in line with similar results for physical health, the compulsory school reform had little or no effect on mortality.

A second set of robustness tests for the validity of our RD design involves estimating jumps at points where there should be not jumps in the treatment distribution. The results reported in Appendix B, do not show any evidence for the presence of jumps in the distribution of the treatment variable in the two subsamples on either side of the cutoff value. 


\section{Estimation results}

We start the results presentation showing the estimated effect of the reform on schooling using local linear regression. In Appendix $\mathrm{C}$ we discuss the cross validation procedure suggested by Imbens and Lemiux (2008) for choosing the optimal bandwidth. This procedure results in an optimal bandwidth that is calculated to be one year (on both sides of the discontinuity) for our cognitive test scores and 3 years for education. For this reason, in the following table we explore the sensitivity of the results to a range of bandwidths that goes from 1 to 3 years around the discontinuity.

We begin by looking at the effect of the reform on schooling outcomes. Table 4 shows the estimated effect of the compulsory school reform on school leaving age conditional on three different samples of educational attainment and 3 different bandwidths $h$. The first row shows the estimated effects for the full sample where dependent variable is the age of left full-time education as recorded in ELSA. Such estimates present two main problems. First, this variable is truncated from above (at age 19). Second it considers the average effect of the reform across all responders including those with higher educational attainment. As expected, the estimated effect of the reform is very poor in this sample. Except for females in the larger bandwidth, in fact, the coefficients are not significantly different from zero. The second row considers the same dependent variable, but excluding people that left full time education at or after the age of 19. This sample excludes all individuals with at least some college attainment, but it still includes many respondents that regardless of the reform would leave the school after the age of 15 (the "always-takers"). In this case, if we look at the smallest bandwidth $h=1$, the estimated effect of the reform is significant only for females. More generally, the estimated coefficients for males are about half of those estimated for females. This result is consistent with Table 1 and Figure 2. Finally, the third row shows the results for the most concentrated sample, which includes only individuals who left full-time education at before the age of 16. This sample is the most important for our estimation strategy, because it should contain the biggest fraction of "compliers", i.e. those who increase of one years their educational attainment as a consequence of the reform. For this sample, the effect of the reform is large and statistically significant at $1 \%$ level for each bandwidth and for both males and females.

The next step is to evaluate the effect of the exogenous increase in education on cognitive outcomes of interest. Table 5 reports estimates of the education effect on cognitive abilities. All test scores have been standardized by subtracting off their mean and dividing by their standard 
deviation. We make use of the 2SLS estimator in order to obtain directly the correct standard errors, robust to heteroscedasticity and clustered at month of birth and wave level. The first set of rows shows the estimated education effect for the sample leaving school at or before the age of 16 (that correspond to the first step in the third row of Table 4), while the second set shows the estimated coefficients conditional on the broader sample including those leaving school up to age 19. We do not report the results for the full sample because of the weak first step shown in Table 4. In the smallest sample, the effect of education seem to be positive for both males and females. However, the standard error for females are larger and so the corresponding coefficients are significant only at $10 \%$ level when we consider 2 or 3 years around the discontinuity. The results are quite different for executive functioning, where the coefficients are statistically significant (at least at $10 \%$ level) only for males. With regard to the magnitudes of these effects, the effect of education on memory is of about half of a standard deviation for males and around 0.4 for females. The effect on executive function for males ranges between .32 and .63 of the standard deviation ${ }^{4}$. When we include in the sample also individuals with higher level of education attainment, as in the second set of rows (Age left $<19$ ), the sign and the magnitude of our coefficients are similar but the estimated standard errors increase in particular for males. For males, the inclusion of respondents with higher level of educational attainment only increase the standard errors of our estimates. This means that there are no gains in increasing the sample size because there are too few males affected by the reform that left full time after the age of 16 .

To evaluate the robustness of our results further, Table 6 reports the estimated treatment effect of education on cognitive abilities using polynomial regression instead of the local linear framework above. We presents the results according to different polynomial orders $k$ and bandwidths $h$. In the smallest sample (age left $<16$ ), the table shows significant coefficients on memory test in particular for males until the fourth order polynomial. Consistent with the local linear estimates, we have significant coefficients on executive function only for males. As before, if we consider also higher level of education attainment (conditional on leaving before 19) we do not find significant effects of education. As before, standard errors are larger for females, with coefficient in many case significant only at $10 \%$ level. On balance, the estimated effects of education on cognitive abilities seem to be robust across specifications and method of estimations.

\footnotetext{
${ }^{4}$ when we use different methods of construction of the executive function index the coefficient are very similar but the standard errors are usually greater
} 
Having estimated the impact of reform on cognitive abilities, the last step is to evaluate the effect of the same reform on two measure of social participation and quality of life (CASP 19). Table 7 reports estimates of the education effect on these two measures using local linear regression method as in Table 5. As before, the two measures have been standardized by subtracting off their mean and dividing by their standard deviation. The results show a positive effect of the increase in education on our measure of social participation for males in the low educational sample, but not for females. This results are statistically significant at least at $10 \%$ level only in the lower educational attainment group when we consider 3 years before and after the reform implementation. We estimate, instead, negative but not statistically significant effect of education on quality of life for both males and females ${ }^{5}$.

\section{Conclusions}

In this paper we use data from 3 waves of English Longitudinal Study on Ageing (ELSA) to estimate the causal effect of education on cognitive abilities using the 1947 increase in compulsory school leaving age in England, Scotland and Wales. This school reform had dramatic effects on educational attainment on a big fraction (around 50\%) of the population just after the cut-off point of 1st April of 1947. At the same time this reform shows very small spillover on people with higher level of educational attainment, particularly for males.

We use a fuzzy regression discontinuity design to estimate the causal effect on the additional year of education induced by this policy change. The results show a positive and significant causal effect on old age memory of less-educated people. These results confirm similar findings in Glymour et al. (2006) that found an effect on memory using compulsory school changes in US. We found also a positive effect of the reform on males' executive function ability measured using an index based on the verbal fluency and letter cancellation tests. These findings seem to be robust to a number of different specifications and methods of estimation.

Whilst some concern may be raised about the fact that our outcome variables are observed at older ages and as such differential mortality patterns of various may be driving our results, we

\footnotetext{
${ }^{5}$ Since the social participation variables come from the self-completion component of the ELSA instrument there is a concern that non-response patterns to this element of the survey may affect our estimates. In order to verify this we performed the same estimation of the effect of education on the cognitive measures in Table 5 using just the subsample of respondent to self-completion questionnaire. The results, not reported to conserve space, do show differences for females. In particular, the estimate effect of education on memory are no longer statistically significant which may, in turn, explain why we don't find evidence of social participation mechanism for females in this sample.
} 
have argued that our particular econometric method - focusing as it does on discontinuities at the treatment date - is robust to such issues and, if anything, we may be underestimating the true effect given a plausible signing of any possible bias. In addition, our full set of date-of-birth and year controls are flexible enough to adequately capture any broader age-related decline in cognitive abilities that will undoubtedly be present in our sample.

In addition to our analysis we have discussed the possible mechanism by which education might be thought to affect cognitive abilities at old age. Taking our evidence together with the important evidence from other studies on the effect of this reform on other outcomes (Oreopoulos, 2006, Clark et al., 2008 and Jürges at al, 2009) it seems possible to say that these effects do not come about via changes to health or mortality. Instead, one needs to look for channels involving earnings (where the reform did have a significant causal effect). Two possibilities emerge. One is that greater earnings and incomes that resulted from the reform have enabled individuals to engage in greater social and cultural participation over their life-course (such as membership of clubs and societies, attendance of events and museums etc.) which in turn have staved off age-related cognitive decline. Our analysis provides some weak evidence for the existence of this channel. But given the strength of our main findings, it seems more natural to conclude that the other possibility, whereby increased earnings and incomes from the reform are reflective of either higher employment or more cognitively demanding and productive occupations which themselves have positive implications for life-course trajectories of cognitive function, is equally if not more important. Given the labor market patterns in these cohorts born in the 1930s, this latter finding would also be in accordance with our finding of stronger effects for males than for females, although some caveats must be noted here due to fact that the first stage regressions (the effect of the reform on schooling outcomes themselves) are somewhat different for men than for women.

Finally, some concern arise over the magnitude of this effect, around half of the standard deviation for one more year of schooling. Diminishing marginal returns to school inputs might be a reasonable explanation for such big effect since people affected by the reform are those in the lower tail of the education distribution. Our findings add a new important element in the evaluation of compulsory school laws that continue to exist and are frequently updated in every developed country. Moreover, the broader issue of the effect of education on old age cognitive abilities is especially important in an aging society where preventing or delaying the age related decline in physical and cognitive abilities is becoming a fundamental target for health, labor and fiscal policy. 


\section{References}

Acemoglu D. and Angrist J.D. (2001), "Consequences of Employment Protection? The Case of the Americans with Disabilities Act". Journal of Political Economy, 109(5): 915-957.

Angrist, J. D. and Krueger, A. B. (1991), "Does Compulsory School Attendance Affect Schooling and Earnings?". The Quarterly Journal of Economics, 106(4): 979-1014.

Ashenfelter O. and Rouse C., 1998. "Income, Schooling, And Ability: Evidence From A New Sample Of Identical Twins". The Quarterly Journal of Economics, 113(1): 253-284.

Banks J., and Oldfield Z. (2007), "Understanding pensions: Cognitive functions, numerical ability and retirement saving." Fiscal Studies, 28(2): 143-170.

Becker G.S., Murphy K. (1988), "A Theory of Rational Addiction". Journal of Political Economy, 96: 675-700.

Card D. (2001), "Estimating the Return to Schooling: Progress on Some Persistent Econometric Problems." Econometrica, Econometric Society,69(5): 1127-1160.

Case A., and Paxson C.H. (2009), "Early life health and cognitive function in old age." American Economic Review, 99: 104-109.

Ceci S. and Williams W.M. (1997), "Schooling, Intelligence, and Income" . American Psychologist, 52,(10): $1051-1058$

Clark D. and Royer H. (2008), "The Effect of Education on Adult Mortality and Health: Evidence from Britain", Mimeo.

Cunha F., and Heckman J. (2007), "The technology of skill formation." American Economic Review, 97: $31-47$.

Cunha F., and Heckman J. (2008). "Formulating, Identifying and Estimating the Technology of Cognitive and Noncognitive Skill Formation". Journal of Human Resources, 43(4).

Currie J. (2009), "Healthy, wealthy, and wise: Socioeconomic status, poor health in childhood, and human capital development." Journal of Economic Literature, 47: 87-122.

de Jager C.A., Budge M.M., and Clarke R. (2003), "Utility of TICS-M for the assessment of cognitive function in older adults." International Journal of Geriatric Psychiatry, 18: 318-324.

Folstein M.F., Folstein S.E., and McHugh P.R. (1975), "Mini-Mental State: A practical method for grading the cognitive state of patients for the clinician." Journal of Psychiatric Research, 12(3): 189-198.

Glymour, M.M. Kawachi, I. Jencks, C.S. Berkman, L.F. (2008), "Does childhood schooling affect old age memory or mental status? Using state schooling laws as natural experiments". Journal of Epidemiology and Community Health, 62(6): 532-537.

Grossman M. (1972), "On the concept of health capital and the demand for health." The Journal of Political Economy, 80(2): 223-255.

Heckman J., Moon S., Pinto R., Savelyev P.A. and Yavitz A. (2010) "The Rate of Return to the High Scope Perry Preschool Program". Journal of Public Economics, 94: 114-128.

Herrnstein R. , Murray C.(1994), “ The Bell curve”. The Free Press, New York.

Hertzog C., Kramer A.F., Wilson R.B., and Lindenberger U. (2008), "Enrichment effects on adult cognitive developments. Can the functional capacity of older adults be preserved and enhanced?" Psychological Science in the Public Interest, 9: 1-65. 
Hyde, M. , Wiggins, R.D. , Higgs, P. and Blane, D.B. (2003), " A measure of quality of life in early old age: the theory, development and properties of a needs satisfaction model (CASP-19)". Aging and Mental Health, 7 (3):186-194.

Imbens, G. W. and Angrist, J. D. (1994), "Identification and Estimation of Local Average Treatment Effects". Econometrica, 62(2): 467-75.

Imbens, G.W., Lemieux, T. (2007), "Regression discontinuity designs: A guide to practice". Journal of Econometrics, 142(2): 615-635.

Jürges, H., Kruk E. and Reinhold S. (2009), "The Effect of Compulsory Schooling on Health - Evidence from Biomarkers". MEA Discussion Paper 183-09.

Le Carret N., Lafont S., Letenneur L., Dartigues F., et al. (2003), "The effect of education on cognitive performances and its implication for the constitution of the cognitive reserve." Developmental Neuropsychology, 23: 317-337.

Lee D.S. and D.Card (2008) "Regression Discontinuity Inference with Specification Error". Journal of Econometrics, 142(2): 655-674.

Lee D.S. and Lemieux T. (2009), "Regression Discontinuity Designs in Economics". NBER Working Papers 14723, National Bureau of Economic Research.

Lleras-Muney (2005), "The Relationship Between Education and Adult Mortality in the U.S". Review of Economic Studies,72(1).

Lochner L. and Moretti E. (2004) "The Effect of Education on Crime: Evidence from Prison Inmates, Arrests, and Self-Reports". American Economic Review, 94(1):155-189.

Mazzonna and Peracchi (2009), "Aging, cognitive abilities and retirement in Europe". CEIS Research Paper 152.

Oreopoulos P. (2006) "Estimating Average and Local Average Treatment Effects of Education when Compulsory Schooling Laws Really Matter". American Economic Review, 96(1): 152-175.

Rohwedder, S., and R. J. Willis (2010), "Mental Retirement". Journal of Economic Perspectives, 24(1): $119-38$.

Spence, A. M. (1973). "Job Market Signaling"”. Quarterly Journal of Economics, 87 (3): 355-374.

Steel, N., F. Huppert, B. McWilliams and D. Melzer, 2003, "Physical and cognitive function", in Marmot, M., J. Banks, R. Blundell, C. Lessof and J. Nazroo, (2003) "Health, wealth and lifestyles of the older population in England: The 2002 English Longitudinal Study of Ageing". London, IFS.

Wiggins, R.D., Netuveli, G., Hyde, M., Higgs, P. and Blane, D. (2008), "An empirical evaluation of a self-reported measure of quality of life (CASP-19) across three research settings". Social Research Indicators, 89: 61-77. 
Table 1: Per cent distribution of age left full time education by age and date of birth (Individuals born three years either side of the cut-off date for the 1947 reform

\begin{tabular}{lrrrr}
\hline & \multicolumn{2}{c}{ Males } & \multicolumn{2}{c}{ Females } \\
\hline Age left fte & Before & After & Before & After \\
& $1 / 4 / 1930-31 / 3 / 1933$ & $1 / 4 / 1933-31 / 3 / 1936$ & $1 / 4 / 1930-31 / 3 / 1933$ & $1 / 4 / 1933-31 / 3 / 1936$ \\
\hline 14 & 58.0 & 7.4 & 55.9 & 5.7 \\
15 & 11.8 & 58.3 & 12.1 & 48.3 \\
$16-18$ & 21.0 & 26.3 & 25.7 & 38.5 \\
$19+$ & 9.3 & 8.0 & 6.3 & 7.5 \\
& 100.0 & 100.0 & 100.0 & 100.0 \\
\hline
\end{tabular}

Table 2: Mean and standard deviation of test scores by sex and age left full time education (we select all individuals born five year before and after the cut off date of 1st April 1933).

\begin{tabular}{lrrrr}
\hline & \multicolumn{2}{c}{ Males } & \multicolumn{2}{c}{ Females } \\
\hline & Mean & S.D. & Mean & S.D. \\
\hline Full sample & & & & \\
\hline Memory & 8.81 & 3.35 & 9.58 & 3.30 \\
Exec. func. & -0.09 & 1.59 & 0.08 & 1.62 \\
$\mathrm{~N}$ & 3517 & & 4103 & \\
\hline Age left fte $<19$ & & & & \\
\hline Memory & 8.64 & 3.30 & 9.44 & 3.24 \\
Exec. func. & -0.16 & 1.54 & 0.01 & 1.58 \\
$\mathrm{~N}$ & 3172 & & 3717 & \\
\hline Age left fte $<16$ & & & & \\
\hline Memory & 8.14 & 3.22 & 8.97 & 3.22 \\
Exec. func. & -.38 & 1.46 & -0.22 & 1.56 \\
$\mathrm{~N}$ & 2322 & & 2576 & \\
\hline
\end{tabular}


Table 3: Mean test scores comparison for those born 5 years before and after the 1st April 1933,

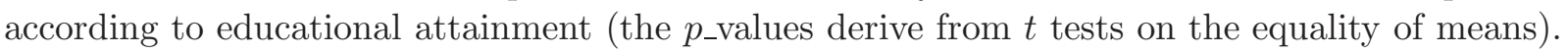

\begin{tabular}{lrrrrrr}
\hline Agel left $<19$ & \multicolumn{3}{c}{ Males } & \multicolumn{3}{c}{ Females } \\
\hline & Before & After & $p$ _value & Before & After & $p$ _value \\
\hline Memory & 8.30 & 8.92 & 0.00 & 8.94 & 9.87 & 0.00 \\
Exec. func. & -0.40 & -0.03 & 0.00 & -0.24 & 0.19 & 0.00 \\
Soc. part. $^{*}$ & 2.74 & 2.90 & 0.00 & 2.41 & 2.58 & 0.00 \\
Casp19* $^{*}$ & 42.24 & 42.24 & 1.00 & 41.71 & 42.63 & 0.00 \\
Child health & 2.19 & 2.12 & 0.11 & 2.35 & 2.38 & 0.48 \\
Father job & 2.64 & 2.66 & 0.56 & 2.62 & 2.57 & 0.12 \\
$N$ & 1423 & 1749 & & 1737 & 1980 &. \\
\hline Agel left $<16$ & \multicolumn{3}{c}{ Males } & & \multicolumn{3}{c}{ Females } \\
\hline & Before & After & $p$ _value & Before & After & $p$ _value \\
\hline Memory & 7.86 & 8.41 & 0.00 & 8.60 & 9.37 & 0.00 \\
Exec. func. & -0.58 & -0.25 & 0.00 & -0.40 & 0.02 & 0.00 \\
Soc. part. & 2.56 & 2.65 & 0.18 & 2.18 & 2.30 & 0.04 \\
Casp19* & 41.55 & 41.28 & 0.49 & 41.18 & 41.82 & 0.10 \\
Child health & 2.27 & 2.21 & 0.26 & 2.45 & 2.38 & 0.23 \\
Father job & 2.79 & 2.81 & 0.55 & 2.74 & 2.71 & 0.50 \\
$N$ & 1121 & 1201 & & 1342 & 1234 & \\
\hline
\end{tabular}

*Soc. part. and CASP19 are taken from the self-completion questionnaire that show a lower response rate with respect the core sample of about $15 \%$.

Soc. part. ranges between 0 and 8; Casp19 range between 0 and 57; Child. health values: 1 excellent, 2 very good, 3 good, 4 fair, 5 poor; father job values: 1 professional and managerial, 2 skilled non-manual, 3 skilled manual, 4 unskilled manual. 
Table 4: Estimated impact of 1947 reform on school leaving age, separated by sex (local linear regression).

\begin{tabular}{llll}
\hline Males & $h=1$ & $h=2$ & $h=3$ \\
\hline Age left fte & .361 & .502 & .121 \\
Age left fte $<19$ & .190 & $.401^{* *}$ & $.347^{* *}$ \\
Age left fte $<16$ & $.616^{* * *}$ & $.680^{* * *}$ & $.667^{* * *}$ \\
\hline Females & & & \\
\hline Age left & .188 & .532 & $1.170^{* * *}$ \\
Age left fte $<19$ & $.811^{* * *}$ & $.617^{* * *}$ & $.676^{* * *}$ \\
Age left fte $<16$ & $.587^{* * *}$ & $.537^{* * *}$ & $.632^{* * *}$ \\
\hline
\end{tabular}

Table reports estimated effects of compulsory school reform on schooling. Columns denotes the bandwidth selection $h$ from 1 to 3 years. Rows indicates three different sample selections: (a) full sample; (b) conditional on leaving before the age of 19; (c) conditional on leaving before the age of 16. All regressions include: a linear function of month of birth and its interaction with the reform dummy; controls for adult height and for survey year. The standard error are robust and clustered at individual level. Significance levels: $\left(^{*}\right) p$-values between 10 and 5 percent; $(* *) p$-values between 5 and 1 percent; (***) $p$-values less than 1 percent.

Table 5: 2SLS estimates of the effect of education on cognitive abilities.

\begin{tabular}{lcllrcc}
\hline & \multicolumn{3}{c}{ Males } & \multicolumn{3}{c}{ Females } \\
\hline Age $<16$ & $h=1$ & $h=2$ & $h=3$ & $h=1$ & \multicolumn{1}{c}{$h=2$} & $h=3$ \\
\hline Memory & $.582^{*}$ & $.484^{* *}$ & $.406^{* *}$ & .419 & $.481^{*}$ & $.359^{*}$ \\
Exec. func. & $.633^{*}$ & $.542^{* *}$ & $.323^{*}$ & -.234 & -.025 & .072 \\
$N$ & 444 & 951 & 1432 & 501 & 991 & 1461 \\
\hline Age $<19$ & & & & & & \\
\hline Memory & .453 & .275 & .175 & .356 & .244 & $.272^{*}$ \\
Exec. func. & 1.114 & .545 & .186 & -.068 & -.021 & .052 \\
$N$ & 649 & 1289 & 1901 & 737 & 1460 & 2212 \\
\hline
\end{tabular}

Table reports 2SLS estimates of the effect of schooling on cognitive test scores. Columns denotes the bandwidth selection $h$ from 1 to 3 years. Rows indicates two different sample selection: (a) conditional on leaving before the age of 19; (b) conditional on leaving before the age of 16. All regressions include: a linear function of month of birth and its interaction with the reform dummy; controls for adult height and for survey year. The standard error are robust and clustered at individual level. Significance levels: $\left(^{*}\right) p$-values between 10 and 5 percent; $(* *) p$-values between 5 and 1 percent; $(* * *) p$-values less than 1 percent. 
Table 6: Polynomial regression estimates of the education effect on cognitive test scores.

\begin{tabular}{|c|c|c|c|c|c|c|}
\hline \multirow[t]{2}{*}{ Age $<16$} & \multicolumn{3}{|c|}{ Males } & \multicolumn{3}{|c|}{ Females } \\
\hline & \multicolumn{6}{|c|}{ Memory } \\
\hline pol. order & $h=5$ & $h=8$ & $h=10$ & $h=5$ & $h=8$ & $h=10$ \\
\hline$k=2$ & $.479^{* *}$ & $.331^{*}$ & .249 & $.434^{*}$ & .266 & .232 \\
\hline$k=3$ & $.519 *$ & $.580^{* *}$ & $.522 * *$ & .578 & $.509 *$ & $.408^{*}$ \\
\hline \multirow{2}{*}{$k=4$} & .567 & $.530 *$ & $.551^{* *}$ & .553 & $.609^{*}$ & $.522^{*}$ \\
\hline & \multicolumn{6}{|c|}{ Exec. func. } \\
\hline$k=2$ & .352 & .082 & .173 & -.011 & .094 & .185 \\
\hline$k=3$ & $.774 * * *$ & $.492 * *$ & .238 & -.134 & .013 & .048 \\
\hline$k=4$ & .450 & $.648^{* *}$ & $.581 * *$ & -.291 & -.173 & -.128 \\
\hline$N$ & 2322 & 3492 & 4203 & 2576 & 3899 & 4698 \\
\hline \multicolumn{7}{|l|}{ Age $<19$} \\
\hline & \multicolumn{6}{|c|}{ Memory } \\
\hline pol. order & $h=5$ & $h=8$ & $h=10$ & $h=5$ & $h=8$ & $h=10$ \\
\hline$k=2$ & .496 & .037 & -.038 & $.335^{*}$ & .184 & $.207^{*}$ \\
\hline$k=3$ & .206 & .596 & .294 & .285 & .344 & .256 \\
\hline \multirow[t]{2}{*}{$k=4$} & .056 & .331 & .458 & .333 & $.372^{*}$ & .341 \\
\hline & \multicolumn{6}{|c|}{ Exec. func. } \\
\hline$k=2$ & .127 & -.042 & .039 & .044 & .082 & .142 \\
\hline$k=3$ & .778 & .421 & .055 & -.078 & .029 & .050 \\
\hline$k=4$ & .497 & .771 & .591 & -.167 & -.103 & -.077 \\
\hline$N$ & 3172 & 4811 & 5797 & 3717 & 5678 & 6962 \\
\hline
\end{tabular}

Table reports the 2SLS estimates of the effect of schooling on cognitive test scores using polynomial regression. Columns denotes the bandwidth selection $h$ : 5, 8 and 10 years. Inside each sample selection (as in Table 5), rows indicate the polynomial order $k$ from 3 to 5 . All regressions include: a polynomial function of month of birth (of order $k$ ) and its interaction with the reform dummy; controls for adult height and for survey year. The standard error are robust and clustered at individual level. Significance levels: $\left(^{*}\right) p$-values between 10 and 5 percent; (**) $p$-values between 5 and 1 percent; $(* * *) p$-values less than 1 percent. 
Table 7: 2SLS estimates of the effect of education on social participation and quality of life (CASP19).

\begin{tabular}{lrrrrrr}
\hline & \multicolumn{3}{c}{ Males } & \multicolumn{3}{c}{ Females } \\
\hline Age $<16$ & $h=1$ & $h=2$ & $h=3$ & $h=1$ & $h=2$ & $h=3$ \\
\hline Soc. part. & .569 & .356 & $.412^{*}$ & .144 & -.200 & -.137 \\
Casp 19 & -.381 & -.024 & -.082 & -.477 & -.474 & -.027 \\
$N$ & 393 & 835 & 1237 & 406 & 808 & 1191 \\
\hline Age $<19$ & & & & & & \\
\hline Soc. part. & 1.072 & .277 & .499 & -.104 & -.525 & -.302 \\
Casp 19 & -2.464 & -.383 & -.352 & -.218 & -.255 & -.067 \\
$N$ & 583 & 1135 & 1664 & 622 & 1241 & 1883 \\
\hline
\end{tabular}

Table reports 2SLS estimates of the effect of schooling on social participation and a subjective measure of quality of life (CASP19). Columns denotes the bandwidth selection $h$ from 1 to 3 years. Rows indicates two different sample selection: (a) conditional on leaving before the age of 19; (b) conditional on leaving before the age of 16 . All regressions include: a linear function of month of birth and its interaction with the reform dummy; controls for adult height and for survey year. The standard error are robust and clustered at individual level. Significance levels: $(*)$ $p$-values between 10 and 5 percent; $\left.{ }^{* *}\right) p$-values between 5 and 1 percent; $\left.{ }^{* * *}\right) p$-values less than 1 percent. 
Figure 1: Effect of 1947 reform on fraction leaving full-time education at or before age 14 .

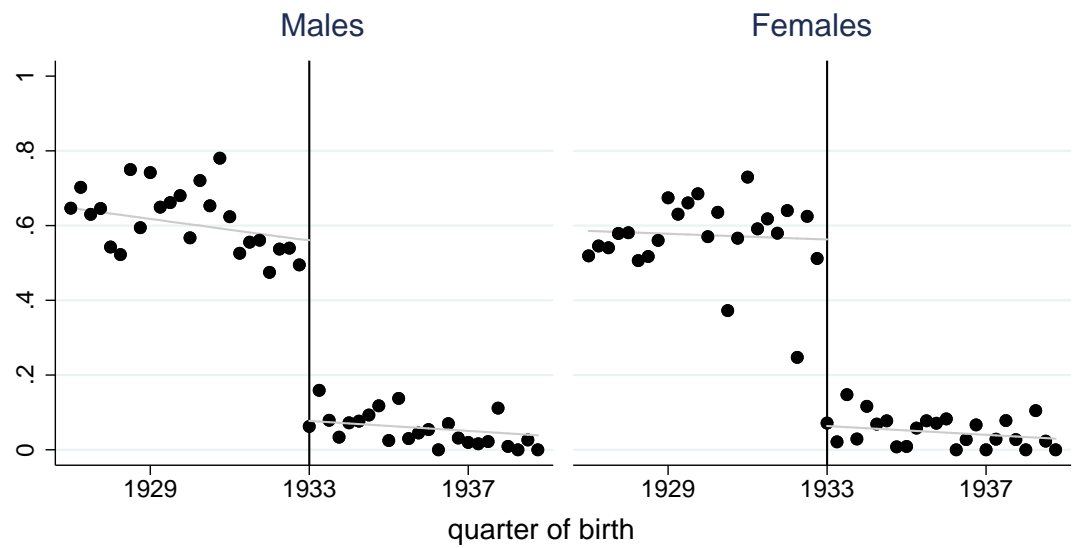

Figure 2: Effect of 1947 reform on fraction leaving at or before age 16 .

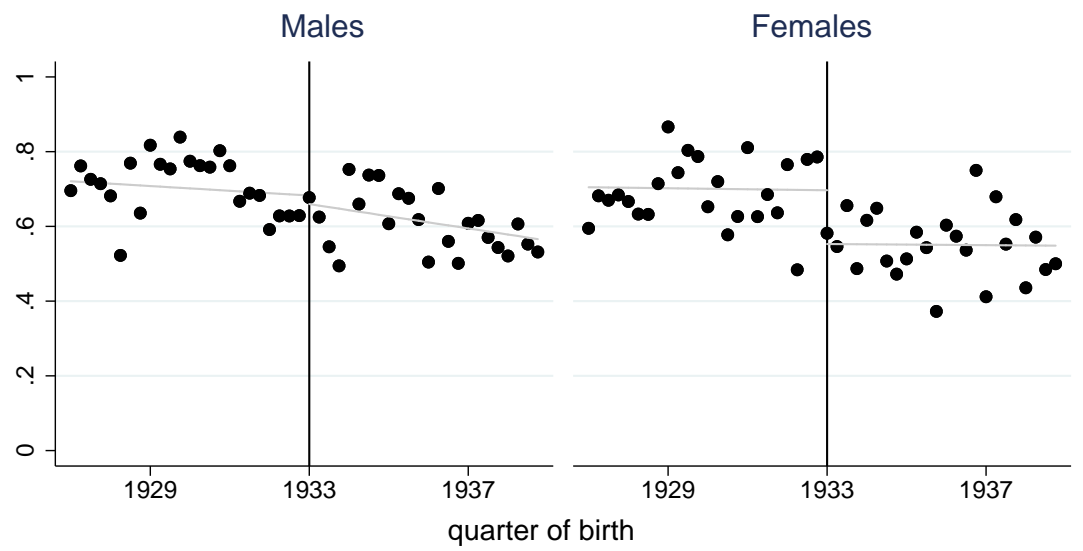


Figure 3: Effect of 1947 reform on fraction leaving at or before age 14 (conditional on leaving before $16)$.

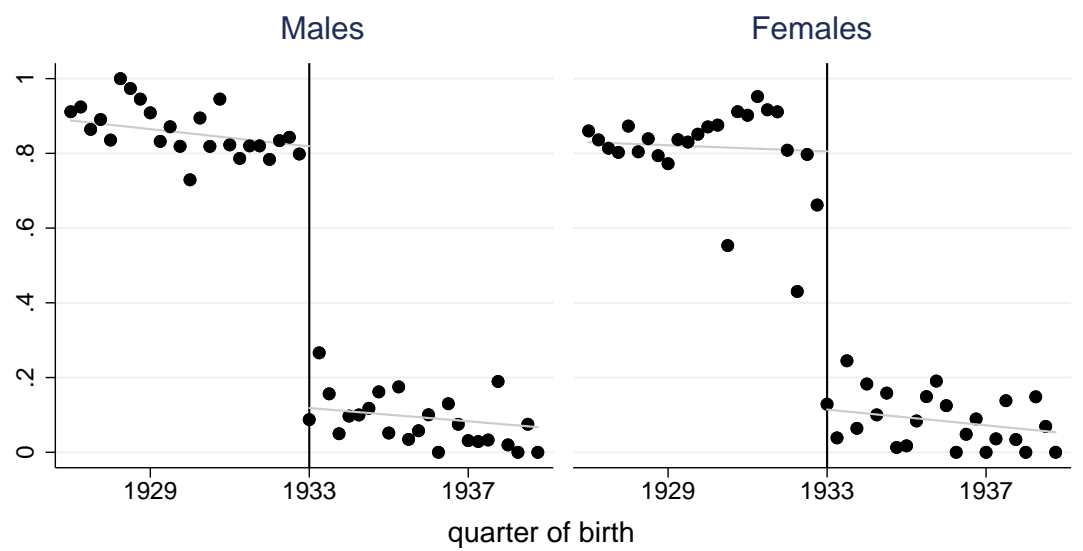

Figure 4: Effect of 1947 reform on Memory (conditional on leaving before 16).

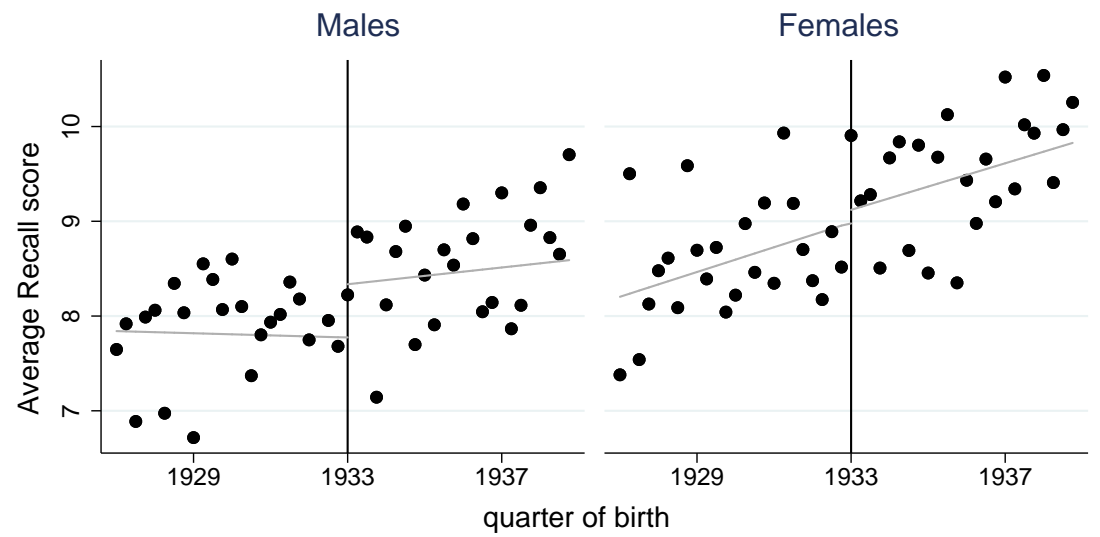


Figure 5: Effect of 1947 reform on Memory (full sample).

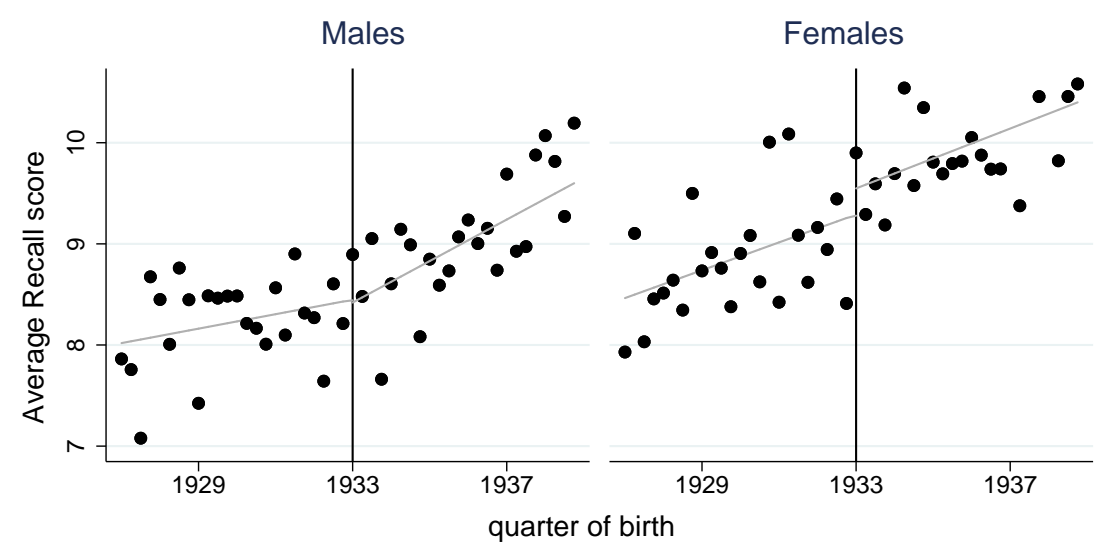

Figure 6: Effect of 1947 reform on Executive functioning (conditional on leaving before 16).

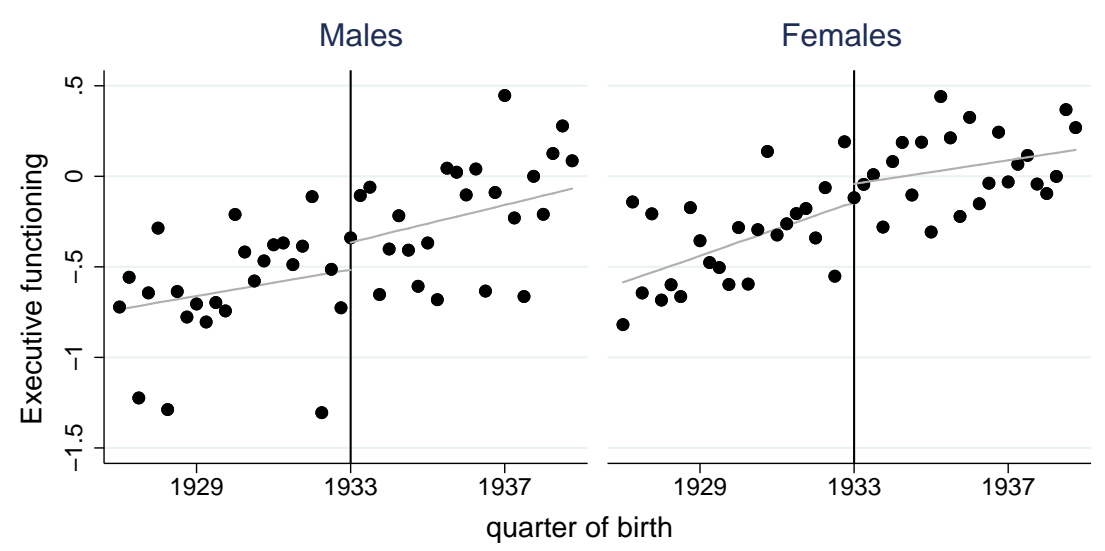


Figure 7: Effect of 1947 reform on Executive functioning (full sample).

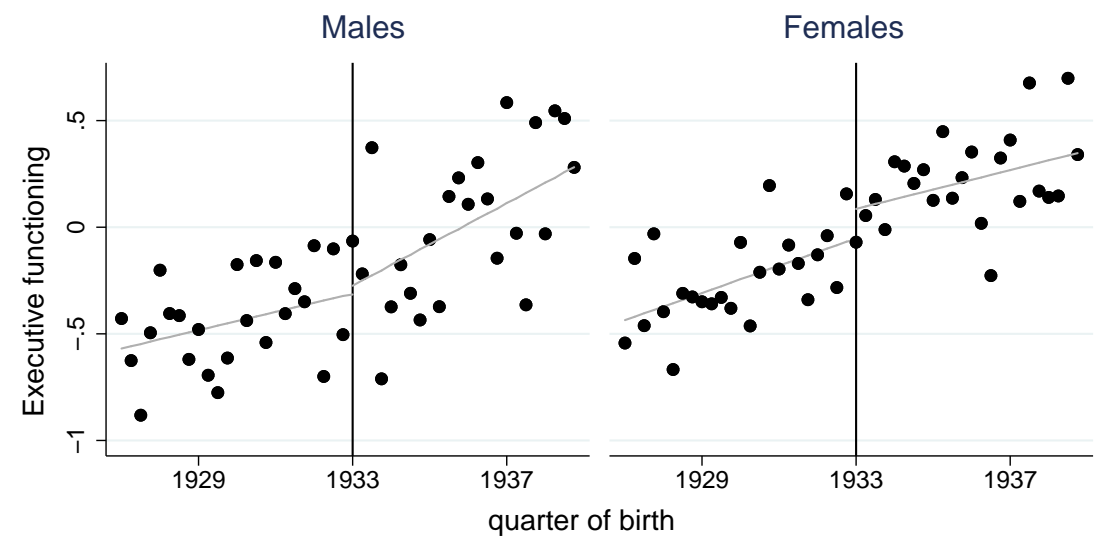

Figure 8: Effect of 1947 reform on Executive functioning (conditional on leaving before 16 and 6 month averages).

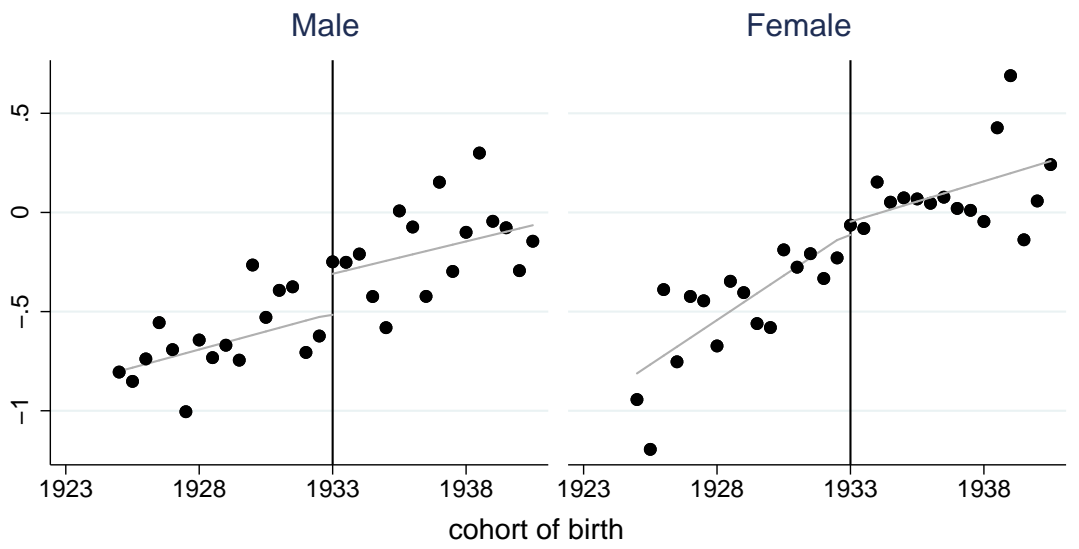


Figure 9: Effect of 1947 reform on Executive functioning (conditional on leaving before 16 and 6 month averages).

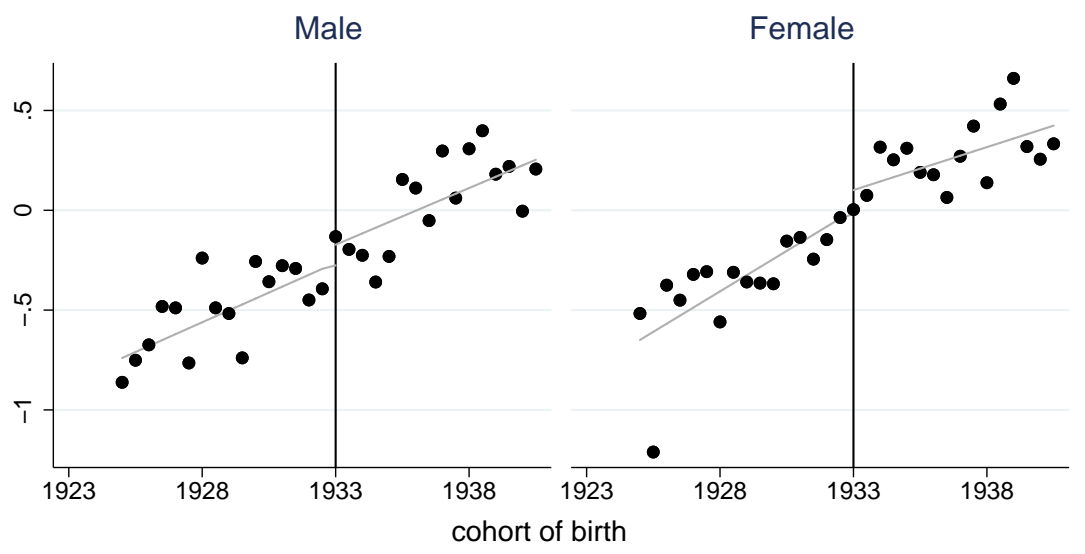




\section{A Measure of quality of life (CASP19) and social and cultural participation}

The questions in the self-completion ask about the respondents' quality of life, social participation and social networks, and the respondents' mental and psycho-social health. From this questionnaire we construct two indexes that we use in our analysis: CASP 19 and social participation.

The CASP 19 is a theoretically grounded measure of quality of life consisting of 19 Likert scaled agreement items spanning four life domains: control, autonomy, self-realization and pleasure. Each life domain contains four or five items which are presented as statements to ELSA respondents in the self completion questionnaire. Each statement is assessed in a four point Likert scale as to the extent to which the description describes a personal feelings about their life (rated as this applies to me: often, sometimes, not often or never) applies to the respondent. The resulting scale scores are summed to form an index of quality of life where a high score indicates "good" quality of life. The range of the scale is from 0 , which represents a complete absence of quality of life, to 57 , which represents total satisfaction of all four domains. In our sample the achieved range goes from 7 to 57 . The original scale was developed in the context of a postal follow-up to members of the Boyd-Orr sample in 2000 (Hyde et al. 2003). A complete evaluation of the psychometric properties of this measure in terms of internal consistency and reliability was made by Wiggins et al. (2008).

The social participation index is based on a selection of 8 questions from two set of questions intended to measure the social and cultural engagement of the respondent. We select from this questions those activities that should be more cognitive demanding. The first set of questions are presented as statements that may apply or not to the respondent. From this set we select the following ones: (1) I read daily newspaper; (2) I have a hobby or pastime; (3) I use internet and/or email. The second set of question ask to the respondent whether or not he is a member of any of some organizations, clubs or societies. From this second set we select the following ones: (1) Political party, trade union or environmental groups; (2) Tenants groups, resident groups, Neighborhood Watch; (3) Education, art or music groups or evening classes; (4) Social clubs; (5) any other organizations, club or societies. The index is composed summing all the activities or membership in which the respondent reports to be involved. As a consequence the index ranges from 0 to 8 . 


\section{B Robustness check}

In this section we report the results from two different tests that we perform to verify the validity of our RD design. The first test verifies whether there are discontinuity in pre-determined characteristics for which we have data, known not to be affected by the treatment. This test is particularly important, because in the presence of other discontinuity, the estimated effect may be attributed erroneously to the treatment of interest. Specifically, we tested the assumption on zero effects on father's last occupation and self-reported childhood health, using the same estimation strategy performed for estimating the treatment effect on cognitive test scores. Table 8 reports the education effect on these two variables using a local linear regression approach around the discontinuity using only the first wave. As shown also in Table 3 the results do not show significant differences in the two groups rejecting the hypothesis of the presence of discontinuity in the observed predetermined characteristics.

A second test for the validity of our RD design involves estimating jumps at points where there should be not jumps in the treatment distribution. As suggested by Imbens and Lemiux (2009) we test for jumps at the median value of the two subsamples on either side of the cutoff value. Specifically, we test for the presence of jumps five year before and after the cutoff date of 1st April of 1933. Table 9 we report the results of this test. For each sex, each column reports the estimated coefficient of a dummy variable on that identifies cohorts born after one of the two "virtual" cutoff point, namely 1928 and 1938. All regressions include a linear function of month of birth and its interaction with the non-discontinuity dummy, controls for adult height and for survey year. As expected, the results does not show any significant coefficients.

\section{Cross validation procedure}

The optimal bandwidth is chosen with a "leave one out" procedure proposed by Imbens and Lemiux (2008). Basically, for each observation $i$ on the left of the cutoff point, we run a linear regression using only observation with value of $\mathrm{X}$ (the treatment determining variable) on the left of $X_{i}$ $\left(X_{i}-h \leq X<X_{i}\right)$, while for observation on the right of the cutoff point we use only those on the right of $X_{i}\left(X_{i} \leq X<X_{i}+h\right)$. We repeat this procedure for each $i$ in order to obtain the whole set of predicted value of $Y$ that can be compared with the actual value of Y. Formally, the 
cross-validation criterion is defined as

$$
C V_{Y}(h)=\frac{1}{N} \sum_{i=1}^{N_{h}}\left(Y_{(i)}-\hat{Y}\left(X_{(i)}\right)\right)^{2},
$$

where $\hat{Y}\left(X_{(i)}\right)$ represent the predicted value of $\mathrm{Y}$ using the above described regression. The optimal bandwidth is that value of $h$ that minimize the criterion function. In our case we have to perform this procedure 3 times: one for the first stage regression, and two for the two cognitive outcome of interest. However, Imbens and Lemiux (2008) suggest to use same bandwidth for both outcome and treatment equation and use the smallest bandwidth selected by the cross-validation procedures. To avoid problem with seasonality in month of birth we apply the cross validation procedure only on bandwidths equal to multiples of year of birth, from 1 to 10 years before and after the cutoff point. The results of this procedures that we do not report to conserve space, suggest that except for except for females' executive function (where the optimal bandwidth is 2 year), the optimal is equal to 1 year.

\section{Polynomial choice}

The second estimation procedure is based on polynomial regression. In this case the problem is the choice of the optimal polynomial order. I make use of the well know Akaike information criteria $(A I C)$ :

$$
A I C=N \ln (\hat{\sigma})^{2}+2 p
$$

where $\hat{\sigma}$ is the mean square error of the regression and $p$ is the number of parameters in the model. The results of this polynomial choice are presented in table 10. The table report the $A I C$ value according to different bandwidth and polynomial order. This allow us to evaluate the robustness of the results according to different bandwidths. From the result presented in the table do not emerge a defined choice for the polynomial order. More in general, for both males and females the optimal order of the polynomial increases as we increase the bandwidth, but it is usually bigger for males then for females. 
Table 8: 2SLS estimates of the effect of education on predetermined characteristics

\begin{tabular}{lrrrccc}
\hline & \multicolumn{2}{c}{ Males } & \multicolumn{3}{c}{ Females } \\
\hline Age $<16$ & $h=1$ & $h=2$ & $h=3$ & $h=1$ & $h=2$ & $h=3$ \\
\hline fat. last job & .684 & -.124 & .059 & -.179 & .333 & -.022 \\
Child. health & .537 & -.105 & .020 & .342 & -.007 & -.242 \\
\hline Age $<19$ & & & & & & \\
\hline fat. last job & 1.323 & -.300 & .189 & .007 & .362 & .075 \\
Child. health & -5.236 & -1.616 & -.591 & .268 & .091 & .028 \\
\hline
\end{tabular}

Table 9: Test of discontinuities at non discontinuity points

\begin{tabular}{lcccc}
\hline Age left $<16$ & \multicolumn{2}{c}{ Males } & \multicolumn{2}{c}{ Females } \\
\hline & before & after & before & after \\
\hline Non disc. point & -.006 & .004 & -.046 & -.003 \\
$N$ & 1935 & 2322 & 2312 & 2414 \\
\hline Age left $<19$ & & & & \\
\hline Non disc. point & .075 & .042 & -.116 & -.017 \\
$N$ & 2441 & 3428 & 3009 & 3993. \\
\hline
\end{tabular}

Table reports the coefficient of a set of OLS regressions with a dummy variable that identifies the cohorts born after two non-discontinuity points, namely five years before the first cohort affected by the 1947 reform (1928) and the second five years after (1938). In each regression the sample includes respondents born five years before and after the non discontinuity point. All regressions include: a linear function of month of birth and its interaction with the virtual reform dummy; controls for adult height and for survey year. The standard error are robust and clustered by month of birth and survey year. Significance levels: $\left(^{*}\right) p$-values between 10 and 5 percent; $\left(^{* *}\right) p$-values between 5 and 1 percent; $(* * *) p$-values less than 1 percent. 
Table 10: Polynomial order choice according to different bandwidth (years).

\begin{tabular}{|c|c|c|c|c|c|c|}
\hline & & & \multicolumn{2}{|c|}{ Males } & \multicolumn{2}{|c|}{ Females } \\
\hline \multirow[t]{16}{*}{ Memory } & Years & Polynomial & $\mathrm{N}$ & $\mathrm{AIC}$ & $\mathrm{N}$ & $\mathrm{AIC}$ \\
\hline & 5 & 1 & 2322 & 11988.56 & 2576 & 13270.69 \\
\hline & 5 & 2 & 2322 & 11986.11 & 2576 & 13271.36 \\
\hline & 5 & 3 & 2322 & 11989.93 & 2576 & 13275.22 \\
\hline & 5 & 4 & 2322 & 11992.97 & 2576 & 13278.85 \\
\hline & 5 & 5 & 2322 & 11993.03 & 2576 & 13271.7 \\
\hline & 8 & 1 & 3492 & 17918.27 & 3899 & 20064.6 \\
\hline & 8 & 2 & 3492 & 17904.69 & 3899 & 20060.93 \\
\hline & 8 & 3 & 3492 & 17902.9 & 3899 & 20060.69 \\
\hline & 8 & 4 & 3492 & 17902.36 & 3899 & 20064.18 \\
\hline & 8 & 5 & 3492 & 17900.99 & 3899 & 20062.61 \\
\hline & 10 & 1 & 4203 & 21560.5 & 4698 & 24158.79 \\
\hline & 10 & 2 & 4203 & 21553.79 & 4698 & 24149.74 \\
\hline & 10 & 3 & 4203 & 21549.53 & 4698 & 24151.26 \\
\hline & 10 & 4 & 4203 & 21552.44 & 4698 & 24149.47 \\
\hline & 10 & 5 & 4203 & 21551.56 & 4698 & 24148.66 \\
\hline \multirow[t]{16}{*}{ Exec. func. } & Years & Polynomial & $\mathrm{N}$ & $\mathrm{AIC}$ & $\mathrm{N}$ & $\mathrm{AIC}$ \\
\hline & 5 & 1 & 2322 & 14574.82 & 2576 & 15856.63 \\
\hline & 5 & 2 & 2322 & 14574.7 & 2576 & 15859.4 \\
\hline & 5 & 3 & 2322 & 14574.42 & 2576 & 15862.74 \\
\hline & 5 & 4 & 2322 & 14576.58 & 2576 & 15866.54 \\
\hline & 5 & 5 & 2322 & 14579.1 & 2576 & 15865.46 \\
\hline & 8 & 1 & 3492 & 21998.15 & 3899 & 23970.38 \\
\hline & 8 & 2 & 3492 & 21997.77 & 3899 & 23972.89 \\
\hline & 8 & 3 & 3492 & 21992.66 & 3899 & 23975.09 \\
\hline & 8 & 4 & 3492 & 21996.23 & 3899 & 23975.36 \\
\hline & 8 & 5 & 3492 & 21996 & 3899 & 23975.02 \\
\hline & 10 & 1 & 4203 & 26585.13 & 4698 & 28904.11 \\
\hline & 10 & 2 & 4203 & 26586.59 & 4698 & 28901.72 \\
\hline & 10 & 3 & 4203 & 26585.41 & 4698 & 28905.24 \\
\hline & 10 & 4 & 4203 & 26584.27 & 4698 & 28906.14 \\
\hline & 10 & 5 & 4203 & 26582.06 & 4698 & 28902.69 \\
\hline
\end{tabular}

